\title{
ChITOSAN THERMOGELS FOR LOCAL EXPANSION AND DELIVERY OF TUMOR-SPECIFIC T LYMPHOCYTES TOWARDS ENHANCED CANCER IMMUNOTHERAPIES
}

\author{
Anne Monette $^{* 1}$, Caroline Ceccaldi ${ }^{* 2}$, Elias Assaad ${ }^{2}$, Sophie Lerouge ${ }^{\& 2}$, Réjean Lapointe ${ }^{\& 1}$ \\ 1. Laboratoire d'Immuno-Oncologie, ICM, U de Montréal/CRCHUM, Montréal, QC, Canada. \\ 2. Laboratory of Endovascular Biomaterials (LBeV), École de technologie supérieure (ETS)/ CHUM \\ Research Center (CRCHUM), Montréal, QC, Canada. \\ * and \& : equivalent contribution to the work
}

Corresponding authors:

Sophie Lerouge:

Phone +1 514396 8836; Fax +1 514412 7785; e-mail sophie.lerouge@etsmtl.ca

Réjean Lapointe:

Phone +1 5148908000 ext. 25489; Fax +1 514; e-mail rejean.lapointe@umontreal.ca

\begin{abstract}
:
The success of promising anti-cancer adoptive cell therapies relies on the abilities of the perfused $\mathrm{CD}^{+} \mathrm{T}$ lymphocytes to gain access to and persist within the tumor microenvironment to carry out their cytotoxic functions. We propose a new method for their local delivery as a living concentrate, which may not only reduce the numbers of cells required for treatment but also enhance their site-specific mobilization. Using combinations of sodium hydrogen carbonate and phosphate buffer as gelling agents, novel injectable chitosan-based biocompatible thermogels (CTGels) having excellent mechanical properties and cytocompatibility have been developed. Three thermogel formulations with acceptable physicochemical properties, such as physiological $\mathrm{pH}$ and osmolality, macroporosity, and gelation rates were compared. The CTGel2 formulation outperformed the others by providing an environment suitable for the encapsulation of viable $\mathrm{CD}^{+} \mathrm{T}$ lymphocytes, supporting their proliferation and gradual release. In addition, the encapsulated $\mathrm{T}$ cell phenotypes were influenced by surrounding conditions and by tumor cells, while maintaining their capacity to kill tumor cells. This strongly suggests that cells encapsulated in this formulation retain their anti-cancer functions, and that this locally injectable hydrogel may be further developed to complement a wide variety of existing immunotherapies.
\end{abstract}

\section{Keywords: cancer, immunotherapy, T lymphocytes, chitosan, hydrogel, injectable}




\section{Introduction:}

Systemic adoptive cell therapy (ACT) is an emerging form of cancer immunotherapy showing tremendous potential in clinical studies aimed at treating solid cancers. The success of ACT relies on the expansion of tumour infiltrating lymphocytes (TIL) from patient-derived tumors for their personalized systemic infusion back into individual patients, along with the capacity of these antigen-experienced and activated TIL to access and persist in the tumor microenvironment where they may elicit their cytotoxic, anti-cancer responses [1]. Three main pitfalls of the current clinical protocol keep this promising form of treatment from becoming mainstream: 1) ACT requires the expansion of vast numbers of patient-tumor derived TIL (20-150 billion) for the final GMP-grade infusion product [2], and which, when not possible causes a great number of patients to lose treatment eligibility [3]. 2) TIL expansion using a rapid expansion protocol (REP) over many weeks causes a growth-mediated outcompeting/diminishment in the proportion tumorreactive cells [4,5], and the extended period of time associated to "selected TILs" protocol often does not match with the rapid deterioration of patients $[6,7]$. Though the "young TIL" expansion protocols produce more reactive TIL [4, 5, 8-10], this measure also limits patient eligibility when expanded TIL do not reach the therapeutic numbers required for ACT. 3) Large numbers of TIL must be expanded because their systemic delivery causes many to be lost to non-cancerous sites of inflammation such as the pulmonary micro-vasculature [11, 12]. Another drawback of this anti-cancer treatment is the toxic effects produced by the high-dose bolus interleukin-2 (IL-2) administrated to maintain the TIL in an activated state following ACT [13]. It is clear that the pitfalls of the current TIL-ACT protocol are the result of the systemic TIL administration protocol. This has led us to develop a new method for the local injection of concentrated, three dimensional (3D) TIL cultures into the tumor microenvironment akin to adjuvant postoperative radiation therapy currently applied to cavities formed from tumor resection in cases of advanced tumor stage and margin positivity, and also with the intent to mimic naturally occurring tertiary lymphoid structures associated to positive patient prognosis [14-20].

We hypothesize that the implantation of 3D T cell cultures will provide a means for the delivery of a continuous feed of these cells towards the reduction of tumor burden or of tumor reoccurrence near the site of tumor resection. To that end, the molecular architecture of the scaffold must allow the proliferation and release of functional T cells whose activation state can be influenced by the surrounding conditions, allowing activating and chemoattractant signatures from the tumor microenvironment to accelerate the proliferation, escape, and immunogenicity of the encapsulated cells. It must also allow its precise, local administration in a minimally invasive way (through catheter or needle), its gellifying ahead of its dispersion, and must provide it with the ability to withstand in vivo stress and degradation for the duration of treatment. 
Towards this purpose, chitosan thermogels were developed to act as injectable matrices supporting cellular growth. Chitosan, a deacetylated derivative of chitin, is a natural, biocompatible, nonimmunogenic and biodegradable polysaccharide which has been examined for use towards a wide range of biomedical applications [21-23]. When combined with a weak base such as $\beta$-glycerophosphate (BGP), it can form a solution (a thermogel) having physiological $\mathrm{pH}$ and which gelates at $37^{\circ} \mathrm{C}$ [24]. Though this thermogel has been considered for several biomedical applications, its mechanical properties are very poor and its biocompatibility is limited. Indeed, we and others have shown that the concentration of BGP required to reach rapid gelation $(0.4 \mathrm{M})$ is cytotoxic to cells due to its hyperosmolality [25, 26]. Culture medium incubated with $\mathrm{CH}$-BGP hydrogels prepared with BGP of $0.4 \mathrm{M}$ or above had a cytotoxic effect on cells [26]. Moreover, direct encapsulation of L929 mouse fibroblasts led to poor cell viability and growth (data not shown). These limitations were recently overcome by replacing BGP with a combination of sodium hydrogen carbonate $\left(\mathrm{NaHCO}_{3}\right.$, hereafter called $\left.\mathrm{SHC}\right)$ and phosphate buffer (PB) [26]. This combination greatly enhanced the mechanical properties of the chitosan hydrogel, while keeping its thermosensitive properties, rapid gelation at $37^{\circ} \mathrm{C}$ and low salt concentration, suggesting that it might be ideal for cell encapsulation. In addition to its key role in enhancement of gel mechanical properties, SHC is a porogen which concentration has been shown to influence hydrogel porosity [27]. Indeed, when mixed with an acidic chitosan solution the reaction between $\mathrm{SHC}\left(\mathrm{HCO}_{3}{ }^{-}\right)$and proton $\left(\mathrm{H}^{+}\right)$leads to the generation of carbon dioxide $\left(\mathrm{CO}_{2}\right)[27,28]$. Thus our previous work showed that the final concentration of both gelling agents influences gelation kinetic and porosity, and the modulation of their ratios allows the thermogel formulation to be adjusted according to the specific needs of individual clinical applications [26].

In this study, three different formulations have been investigated with the aim to create injectable chitosan thermogels of different morphologies capable of housing the growth of $3 \mathrm{D}$ cultures of activated $\mathrm{T}$ lymphocytes. Based on our previous results [26], the concentration of PB was fixed to $0.04 \mathrm{M}$ to reach adequate gelation kinetics and injectability, and three different concentrations of SHC were used to obtain hydrogels with different porosities influencing cell proliferation and release: SHC 0.05 M (CTGel1), SHC $0.075 \mathrm{M}$ (CTGel2) and SHC 0.12 M (CTGel3) (see Table 1).

CTGel rheological properties and mechanical strengths were evaluated by rheometry and unconfined compression tests, respectively, and their morphologies were compared by scanning electron microscopy (SEM). CTGel cytocompatibility was determined from the encapsulation of primary $T$ cells expanded from normal donor peripheral blood mononuclear cells (PBMCs). CTGel and supernatant-derived cells numbers, cell viability, phenotype and activation status were recorded over time using microscopy and flow cytometry. The CTGel2 formulation was found to be superior to the others and was further studied to reveal its potential for cancer immunotherapy, as demonstrated from the activation and escape of encapsulated TIL and T cells in response to, and for the killing of their cognate tumor cells. 


\section{Experimental Methods:}

Hydrogels preparation:

Chitosan (Marinard Biotech, Mw $250 \mathrm{kDa}$, DDA $94 \%$ ) was purified using sodium dodecyl sulfate as previously described [26]. Chitosan solution was then obtained by solubilizing purified chitosan in $\mathrm{HCl}(0.1$ M) at $3.33 \%(w / v)$ overnight at room temperature. The resulting chitosan solution was sterilized by autoclaving $\left(20 \mathrm{~min}, 121^{\circ} \mathrm{C}\right.$ ) and was stored at $4{ }^{\circ} \mathrm{C}$ until further use. Gelling agent solutions were prepared by mixing $\mathrm{SHC}$ and $\mathrm{PB}$ at $\mathrm{pH} 8$ (prepared by mixing sodium phosphate dibasic $\left(\mathrm{Na}_{2} \mathrm{HPO}_{4}, \mathrm{SPD}\right.$ ) and sodium phosphate monobasic $\left(\mathrm{NaH}_{2} \mathrm{PO}_{4}, \mathrm{SPM}\right)$ at a ratio of $\left.0.932: 0.068\right)$ in Milli-Q water (EMD Millipore). These were prepared to obtain hydrogels with a final PB:SHC concentration of 0.04 M:0.05 M (CTGel1), 0.04 M:0.075 M (CTGel2) and 0.04 M:0.12 M (CTGel3). Gelling agents were sterilized by filtration through $0.2 \mu \mathrm{m}$ filters and were stored at $4^{\circ} \mathrm{C}$ until further use.

All CTGels were prepared to reach a final chitosan concentration of $2 \%(\mathrm{v} / \mathrm{w})$. Chitosan solution (3.33\%, $\mathrm{v} / \mathrm{w}$ ) was loaded into a syringe and the gelling agent solution was loaded into another (volume ratio of $3: 2$ ). For mixing, the two syringes were joined by a luer lock connector (Qosina, USA), and syringe contents were pushed from side to side for 15 repeats.

\section{Morphology, $\mathrm{pH}$ and osmolality of injectable hydrogels}

After 24 hours of incubation at $37^{\circ} \mathrm{C}$, hydrogels were squeezed through a $0.2 \mu \mathrm{m}$ filter. The $\mathrm{pH}$ of the recovered liquid was then determined using a $\mathrm{pH}$-meter (UltraBasic $\mathrm{pH}$-meter, Denver Instrument, USA) and the osmolality was determined using an AdvancedTM Micro Osmometer 3300 (Advanced Instruments Inc., Norwood, USA). For SEM analysis, gels were frozen at $-20{ }^{\circ} \mathrm{C}$, freeze-dried, cut into sections using a surgical scalpel, and deposited onto double-coated carbon conductive tape before being metalized with gold. Their morphologies were then analyzed using a Hitachi S-3600 SEM.

\section{Rheological properties and mechanical strength:}

The gelation kinetics of CTGels at physiological $\left(37^{\circ} \mathrm{C}\right)$ and room $\left(22^{\circ} \mathrm{C}\right)$ temperature were studied by following their rheological properties using a Physica MCR 301 (Anton Paar, Germany) equipped with coaxial cylinder geometry (CC10/T200). The evolution of the storage (G') and loss (G') moduli was determined in the linear viscoelastic range at a constant shear stress (1 Pa) and at a constant frequency $(1 \mathrm{~Hz})$ over the course of $60 \mathrm{~min}$. The time at which $\mathrm{G}^{\prime}=\mathrm{G}^{\prime \prime}$ represents the gelation time [29] and changes in $G^{\prime}$ indicate the progressive gelation and increase of the elastic properties of the gel over time. The Young's modulus and mechanical strength in compression after $24 \mathrm{~h}$ of gelation at $37{ }^{\circ} \mathrm{C}$ were determined using an ElectroForce 3200 test instrument (Bose Corporation, USA) with a $22 \mathrm{~N}$ load cell. Samples were prepared in $14 \mathrm{~mm}$ inner diameter cylinder molds. Unconfined axial compression of up to $50 \%$ strain was applied at a rate of $0.5 \mathrm{~mm}$ per min. As the hydrogels present non-linear elastic behavior, the secant modulus was calculated as shown in equation 1 as an example for $50 \%$ strain: 
$\mathrm{E}_{50 \%}(\mathrm{kPa})=\left[\left(\mathrm{F}_{50 \%} / \mathrm{S}\right) /\right.$ Strain $] \times 1000$,

where $\mathrm{F}_{50 \%}$ is the force registered at $50 \%$ strain $(\mathrm{N})$ and $\mathrm{S}$ is the cross-sectional area of the specimen $\left(\mathrm{mm}^{2}\right)$. Each experiment was performed in triplicate.

Injection of thermogels into rats:

The injectability and cohesion of injected hydrogel were tested in rats kept under general anesthesia (isoflurane 2.5\%). All in vivo experiments were conducted according to the Canadian Council on Animal Care guidelines for care and use of laboratory animals, and under the supervision of our institutional animal care committee. Chitosan, gelling agent and cell culture medium were mixed at room temperature (RT) at the volume ratio of $3: 1: 1$ to prepare CTGel2 (PB $0.04 \mathrm{M}: S H C 0.075 \mathrm{M}$ ), and then $2 \mathrm{~mL}$ of the solution was immediately implanted either by subcutaneous or intraperitoneal injections using 1 inch-long $23 \mathrm{G}$ needles. Rats were euthanized $10 \mathrm{~min}$ later by intraventricular exsanguinations and thermogels were surgically removed for macroscopic observation.

\section{Ethics Statement:}

The written informed consent procedure for the Centre Hospitalier de l'Université de Montréal (CHUM) kidney cancer tissue and clinical data bank for research purposes was approved by the CHUM ethics committee. Written informed consent was obtained from healthy donors and patients prior to the collection of biological materials and clinical data (kept in confidentiality and which is anonymously numbered).

\section{Cell cultures and conditions:}

The ability of $T$ lymphocytes to grow within and escape from the hydrogel was first verified by expanding these from PBMCs derived from healthy donors, and then on T cell clones and TIL expanded from renal clear cell renal carcinoma (ccRCC) tumors. Prior to CTGel encapsulation, T cells were expanded from PBMCs in Iscove's modified Dulbecco's medium (IMDM) complete medium, composed of IMDM (Invitrogen) supplemented with 7.5\% decomplemented human AB serum (Sigma), 2 mM L-glutamine, 100 $\mathrm{U} / \mathrm{mL}$ penicillin, $100 \mathrm{~g} / \mathrm{mL}$ streptomycin, $10 \mathrm{~g} / \mathrm{mL}$ gentamicin (Wisent), $0.5 \mathrm{mg} / \mathrm{mL}$ anti-CD3 (OKT3, eBioscience) and $1800 \mathrm{U} / \mathrm{mL} \mathrm{IL-2} \mathrm{(PeproTech).} \mathrm{For} \mathrm{TIL} \mathrm{expansion,} \mathrm{freshly} \mathrm{resected} \mathrm{ccRCC} \mathrm{kidney}$ tumors were cut into small fragments and then further homogenized using the gentleMACS tissue dissociator (Miltenyi Biotec, USA). The resulting tumor fragments were cultured in IMDM complete medium supplemented with $1800 \mathrm{U} / \mathrm{mL}$ IL-2 for 15 days, where half of the media was replaced after the first five days, and every three days thereafter as previously described [5]. The anti-gp100 HLA-A2restricted T cell clone (directed against a gp100-derived peptide 209-217 in complex with HLA-A*02, and specifically targeting cancer cell lines SK23-mel and 624-mel) (a kind gift of Mark Dudley; Surgery branch, 
$\mathrm{NCl}, \mathrm{NIH}$ ), was grown using a REP as previously described [30-32]. Briefly, irradiated (5,000 rads) feeder cells $\left(2.5 \times 10^{7}\right)$ and anti-gp100 T cells $\left(5 \times 10^{5}\right)$ were cultured in Aim-V, 7.5\% AB medium; composed of Aim-V (Invitrogen) supplemented with 7.5\% decomplemented human AB serum (Sigma), and $2 \mathrm{mM} \mathrm{L-}$ glutamine, $100 \mathrm{U} / \mathrm{mL}$ penicillin, $100 \mathrm{~g} / \mathrm{mL}$ streptomycin, $10 \mathrm{~g} / \mathrm{mL}$ gentamicin (Wisent), $0.5 \mathrm{mg} / \mathrm{mL}$ anti-CD3 (OKT3) and $300 \mathrm{U} / \mathrm{mL} \mathrm{IL}-2$. The REPs were supplemented with $300 \mathrm{U} / \mathrm{mL} \mathrm{IL}-2$ on day 2, and $20 \mathrm{~mL}$ of the medium was replaced at days 5 and 8 where cells were then maintained at $1 \times 10^{6} \mathrm{cells} / \mathrm{mL}$ and IL-2 was added every 3 days until experiments. Melanoma cell lines SK23-mel, 624-mel, and 586-mel (established at the $\mathrm{NCI} / \mathrm{NIH}$ Surgery Branch), and the breast tumor cell line MDA231 (ATCC) were grown in RPMI 1640 medium supplemented with 10\% heat-inactivated FBS, $2 \mathrm{mM} \mathrm{L-glutamine,} 100 \mathrm{U} / \mathrm{mL}$ penicillin-streptomycin, and $10 \mu \mathrm{g} / \mathrm{mL}$ gentamicin.

\section{Cell encapsulation:}

Under sterile conditions and under a laminar flow hood, CTGel-T cell encapsulation was performed in two successive steps using the following component ratios: $0.6 \mathrm{~mL}$ chitosan solution was first mixed with 0.2 $\mathrm{mL}$ of gelling agents (containing PB and SHC, at double concentration) using two syringes and a luer lock connector. After 15 repeated mixings, the contents were shifted entirely to one of the two syringes. The now empty syringe was replaced with a new one containing $0.2 \mathrm{~mL}$ cells in complete medium supplemented with $1800 \mathrm{U} / \mathrm{mL} \mathrm{IL}-2\left(8 \times 10^{6} \mathrm{cells} / \mathrm{mL}\right)$, and again, the two syringes were joined through a luer lock for 15 rounds of mixing. The CTGel-encapsulated cells ( $1 \mathrm{~mL} /$ well) were then deposited into 24well plates and incubated at $37^{\circ} \mathrm{C}$ with $5 \%$ atmospheric $\mathrm{CO}_{2}$ for $5 \mathrm{~min}$ before being topped with $1 \mathrm{~mL}$ of pre-warmed media and placed back into the incubator until further processing or analysis.

\section{Live/Dead assay:}

CTGels were collected at indicated times post cell-encapsulation. For imaging analysis, the gels were rinsed with IMDM and stained $\left(45 \mathrm{~min}, 37^{\circ} \mathrm{C}\right)$ using green-fluorescent calcein-AM to indicate intracellular esterase activity of living cells and red-fluorescent ethidium homodimer-1 binding to the DNA of dead cells, according to the manufacturer's instructions (LIVE/DEAD Viability/Cytotoxicity kit, Life Technologies). After staining, hydrogels were washed with IMDM and observed using fluorescent microscopy (Leica DM IRB) at a 5x magnification.

\section{Flow cytometry:}

Cells were collected from both the media and the gels at indicated times post cell-encapsulation. Cells in the media were first collected using aspiration with one additional rinsing with IMDM. Cells from the gel were collected by washing gels twice with IMDM, then homogenizing gels using three consecutive cycles of the $\mathrm{h}$ _tumor_01 program of the gentleMACS ${ }^{\mathrm{TM}}$ Dissociator (Miltenyi Biotec, USA), and passing the resulting suspension through a $0.45 \mu \mathrm{m}$ filter fit onto a $50 \mathrm{~mL}$ falcon tubes (Fisher) with two additional PBS washes prior to cell pelleting by centrifugation $\left(4{ }^{\circ} \mathrm{C}, 10 \mathrm{~min}, 1500 \mathrm{rpm}\right.$ ). Cells were counted and 
resuspended in PBS for transfer to $5 \mathrm{~mL}$ polystyrene round bottom FACS tubes (Falcon) where nonspecific binding sites were blocked with human gamma globulin (Jackson ImmunoResearch) and dead cells were labelled for flow cytometry-mediated elimination using a LIVE/DEAD fixable Aqua Dead Cell Stain Kit (Life technologies) for $20 \mathrm{~min}$ at $4{ }^{\circ} \mathrm{C}$. Following a cold PBS wash and centrifugation $\left(4{ }^{\circ} \mathrm{C}, 5\right.$ min, $1500 \mathrm{rpm}$ ), cells were resuspended in cold FACS buffer (PBS containing $0.5 \% \mathrm{BSA}$ and $0.1 \% \mathrm{NaN}_{3}$ ) and were stained for $30 \mathrm{~min}$ at $4{ }^{\circ} \mathrm{C}$ with the following titrated monoclonal antibodies CD3-FITC, CD4APC-H7, CD8-PerCP-Cy5.5, HLA-DR-AF700 (BD Biosciences), and CD25-BV605 (BioLegend). For intracellular marking, cells were washed once with FACS buffer $\left(4^{\circ} \mathrm{C}, 5 \mathrm{~min}, 1500 \mathrm{rpm}\right)$, and were then treated using the FoxP3/Transcription Factor Fixation/Permeabilization Concentrate and Diluent kit (eBiosciences) for $30 \mathrm{~min}$. Cells were then washed with, and resuspended in $1 \mathrm{x}$ cold permeabilization buffer (eBiosciences) for staining with titrated monoclonal antibodies: Granzyme B-APC, Perforin-PE, TNFa-PE-Cy7 and AnnexinV-v450 (BD Biosciences) for $30 \mathrm{~min}$. Cells were washed with, and resuspended in cold FACS buffer for flow cytometry analysis. In multi-parametric FACS analyses, compensation beads (BD Biosciences) stained in parallel to cells were used to compensate for fluorescence spill over. Flow cytometry data was acquired using an LSR Fortessa cell analyzer with DIVA software (BD Biosciences) and data was analyzed using FlowJo V10 software.

\section{CFSE labelling:}

For recognition assays, CFSE labelling was used to identify either gel-encapsulated TIL or the melanoma and breast cancer cell lines. Briefly, cells were labeled using (5-and-6)-carboxyfluorescein diacetate (CFSE) (Molecular probes) diluted in DMSO $(5 \mathrm{mM})$. Cells were first washed twice in PBS to remove any residual serum from the growth media, and were resuspended $\left(1 \times 10^{7}\right.$ cells $\left./ \mathrm{mL}\right)$ in RPMI. CFSE solution was added at 1:1000 (final concentration of $5 \mu \mathrm{M}$ ) for incubation for $15 \mathrm{~min}$ in a $37{ }^{\circ} \mathrm{C}$ water bath with regular mixing. To stop the labeling, FBS (10\% of total volume) was added for 1 min at RT, and cells were washed with RPMI before being centrifuged $\left(4{ }^{\circ} \mathrm{C}, 10 \mathrm{~min}, 1500 \mathrm{rpm}\right)$ and were then resuspended at required concentrations for assays.

\section{Recognition assay:}

Recognition/killing assays were performed using the anti-gp100 T cell clone or TIL and their respective cognate cancer cells and tissues, respectively, and using Boyden Chambers 24 well plate cell culture inserts/transwells having $3 \mu \mathrm{m}$ pore size polyethylene terepththalate bottom membranes (BD Falcon). For assays using anti-gp100 T cells, the REP expanded T cells in Aim- $\mathrm{V}, 7.5 \%$ AB medium supplemented with $300 \mathrm{U} / \mathrm{mL}$ IL-2 were encapsulated at $8 \times 10^{6}$ cells $/ \mathrm{mL}$ of CTGel2, and $0.25 \mathrm{~mL}$ of cell-gel mixture was deposited into the Boyden/transwell top inserts and allowed to solidify for $5 \mathrm{~min}$ at $37{ }^{\circ} \mathrm{C}$. During this time, CFSE-labeled target cancer cell lines were seeded in the bottom wells of 24 well plates. The transwell inserts containing the gel-encapsulated cells were placed within the wells, and were topped with an additional $0.25 \mathrm{~mL}$ of Aim-V, 7.5\% AB medium supplemented with $300 \mathrm{U} / \mathrm{mL}$ IL-2. The assay was allowed 
to continue for a period of 5 days at $37^{\circ} \mathrm{C}$ with $5 \%$ atmospheric $\mathrm{CO}_{2}$, and then all cells were collected from the medium in the 24 well plate below. The TIL recognition assay was performed in the same way with the following modifications: the TIL were CFSE-labeled and gel-encapsulated, IMDM complete medium supplemented with $1800 \mathrm{IU} / \mathrm{mL} \mathrm{IL-2} \mathrm{was} \mathrm{used,} \mathrm{and} \mathrm{the} \mathrm{tumor} \mathrm{fragments} \mathrm{from} \mathrm{which} \mathrm{the} \mathrm{TIL} \mathrm{were}$ originally expanded were placed in the bottom of the 24 well plates. After 5 days, cells were collected from both the bottom media in the 24 well plate wells and the gel in the top insert, as described earlier using the GentleMACS method. Supernatants were used for the detection of IFN-y secretion as evaluated by ELISA, as previously described [33].

Statistical Analysis:

Statistical analysis was performed with GraphPad Prism software, using one-way or two-way ANOVA with Tukey's post-test, as indicated in figure legends.

\section{Results and Discussion:}

\section{Physicochemical and mechanical characterization of CTGels}

Table 1 describes the three CTGel formulations and summarizes the physicochemical data. All gels were found to be at physiological $\mathrm{pH}$ and at near-physiological osmolality (from 308 to $411 \mathrm{mOsm} / \mathrm{L}$ relative to physiological values in the $280-350 \mathrm{mOsm} / \mathrm{L}$ range), which are essential requirements for cytocompatibility allowing cell encapsulation.

CTGel rheological properties observed at 37 and $22^{\circ} \mathrm{C}$ confirmed that formulations led to thermosensitive hydrogels, as shown in Figure 1a, which presents the evolution of the storage (G') and loss (G") modulus of the CTGel2 at both temperatures. At $22{ }^{\circ} \mathrm{C}, \mathrm{G}$ ' and G" remained low for an extended period of time, making the gel easily injectable by extrusion through a needle or a catheter. More importantly, this feature enabled the homogeneous mixing of the cells and CTGel (already at physiological pH) prior to injection. Contrarily, a rapid increase of $\mathrm{G}$ ' was observed at $37^{\circ} \mathrm{C}$. For CTGel1 and CTGel2, gelation occurred within the first minute at $37^{\circ} \mathrm{C}$ (where $\mathrm{G}^{\prime}>\mathrm{G}^{\prime}$ at the beginning of the test) and these presented relatively similar gelation kinetics, with rapid increases of the storage modulus (2405 $\mathrm{Pa}$ and $3490 \mathrm{~Pa}$ after 1 hour, respectively) (Fig. 1b). This rapid gelation and increase in mechanical properties is particularly convenient to obtain a strong and cohesive structure following injection, and particularly one which will not diffuse into other in vivo compartments. By comparison, CTGel3 had a slow gelation kinetic with a delayed gelation time of $12 \mathrm{~min}$, and a poor storage modulus after one hour of gelation at $37{ }^{\circ} \mathrm{C}$. Unconfined compression tests after $24 \mathrm{~h}$ of gelation at $37^{\circ} \mathrm{C}$ confirmed the high mechanical properties of the CTgels, with some advantage for the CTgel1 and CTgel2 relative to the CTGel3 formulation, as shown by the stress-strain curves (Fig. 1C) and by the values of the $E_{50 \%}$ secant modulus (Table 1). These values are much higher than conventional CH-BGP gels (with $0.4 \mathrm{M}$ of BGP) for which the average $E_{50 \%}$ was found to be bellow $5 \mathrm{kPa}$ [26]. While the complete mechanism involved in the formation of these 
thermogels has not yet been completely resolved, our data show that SHC concentration plays a key role in their final mechanical properties.

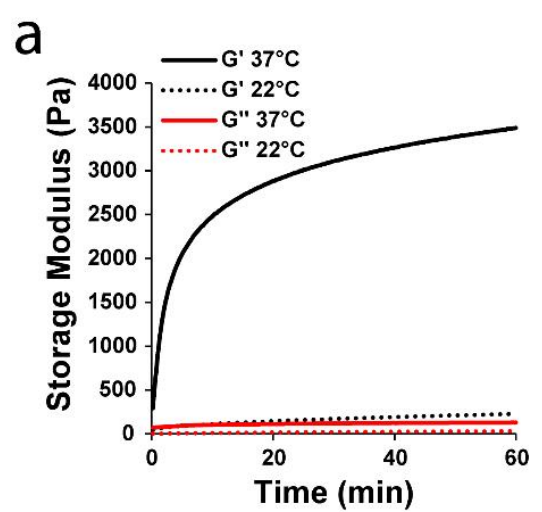

d

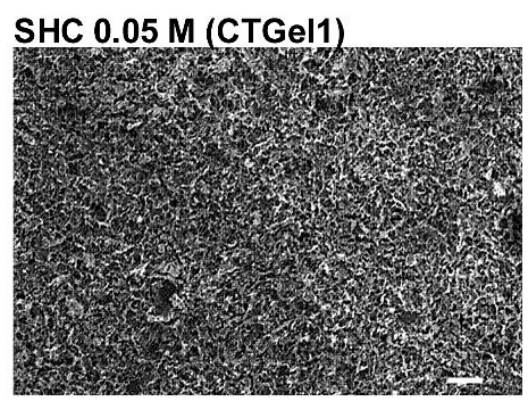

e

\section{Intra-peritoneal injections}

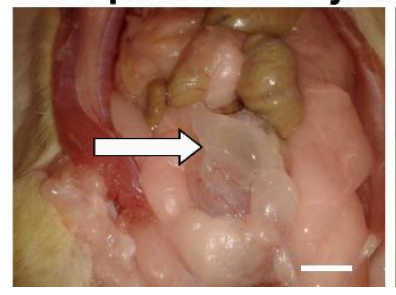

b

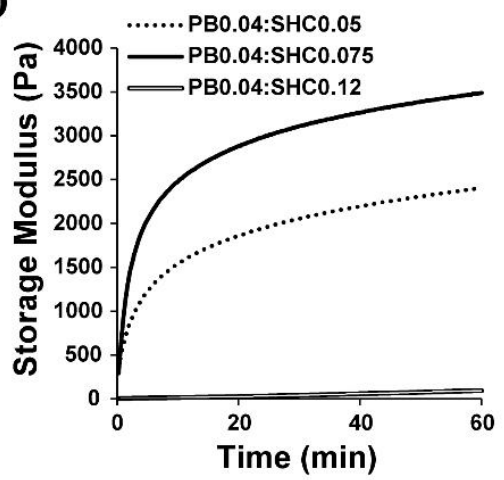

SHC 0.075 M (CTGel2)

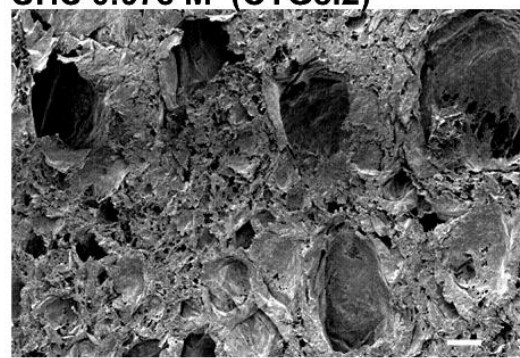

C

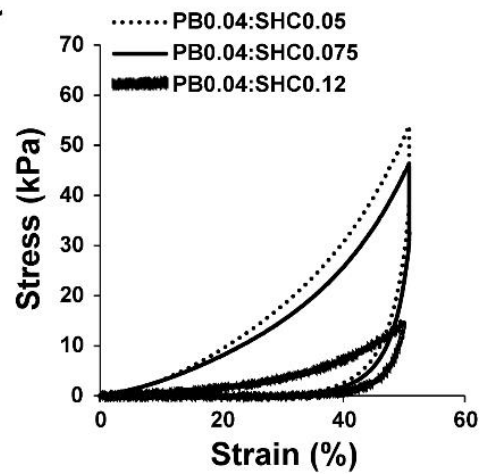

SHC $0.12 \mathrm{M}$ (CTGel3)

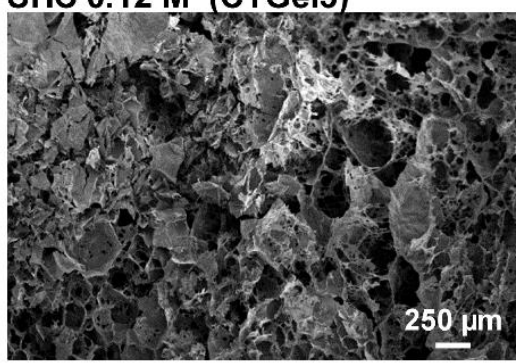

Figure 1. Porosity, mechanical properties, and injectability of CTGels. Rheological properties of hydrogels, where (a) represents the evolution of storage modulus and loss modulus of SHC $0.075 \mathrm{M}$ (CTGel2) at $22{ }^{\circ} \mathrm{C}$ and $37^{\circ} \mathrm{C}$ and (b) the evolution of storage moduli of the three thermogels at $37^{\circ} \mathrm{C}$. (c) Stress-strain curves of thermogels submitted to compression until $50 \%$ of strain, after $24 \mathrm{~h}$ of gelation at $37{ }^{\circ} \mathrm{C}$. (d) SEM images of the ultrastructure of the three CTGel formulations after freeze-drying. (e) Macroscopic observations of CTGel2, 10 min post intra-peritoneal and subcutaneous injections into rats. Results are representative of three independent experiments performed in triplicate.

SEM analysis of the ultrastructure of freeze-dried hydrogels showed differences in pores densities and size distributions (Fig. 1d). As expected, increasing SHC concentration led to increased macroporosity. While direct extrapolations based on pore size should be avoided since freeze-dried porosity does not 
represent the hydrated porosity, these data show that minute changes in SHC concentrations can influence the ultrastructure and will likely impact $\mathrm{T}$ cell proliferation and escape.

Since it appeared to have the best overall characteristics, CTGel2 was selected for in vivo testing in rats. Intraperitoneal and subcutaneous injections of CTGel2 confirmed that it formed an injectable scaffold able to quickly gelify at physiological temperature and form a solid 3D structure in vivo. Ten minutes following injections, rats were euthanazied and the gels were explanted, and these presented a continuous and cohesive structure having a solid appearance (Fig. 1e).

\section{CTGel formulations are permissive to $T$ cell viability and growth}

To determine whether the CTGels were cytocompatible for T cell encapsulation, T lymphocytes expanded from normal donor PBMCs were CTGel-encapsulated as depicted in Figure 2a. After five days, cells were collected from the media and gels for analysis using live/dead staining analyzed by flow cytometry. Results demonstrate that there was no significant difference in cell viability for the cells released from the three CTGel formulations relative to the control cells collected from the medium ( 90\%) (Fig. 2b\&c). On the contrary, significant differences were observed for the cell viability of encapsulated $T$ cells as a function of CTGel formulation. The viability of cells encapsulated in CTGel2 $(90.33 \% \pm 3.79)$ was largely superior to those isolated from the other two formulations (CTGel1: 59.33\% \pm 8.08 ; CTGel3: $65.67 \% \pm 7.77$; $\mathrm{p}<0.001$, Fig. 2c).

a

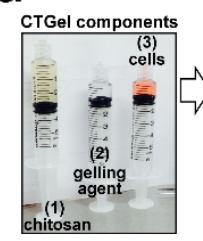

b

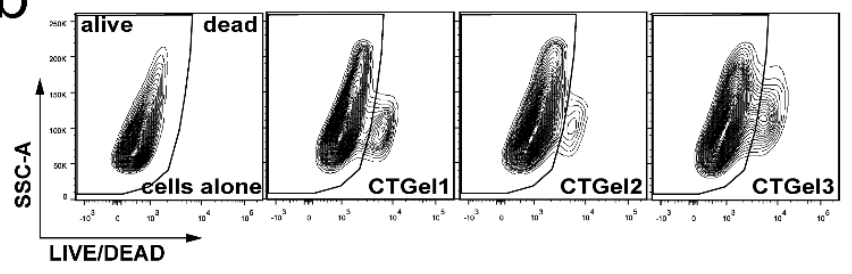

C

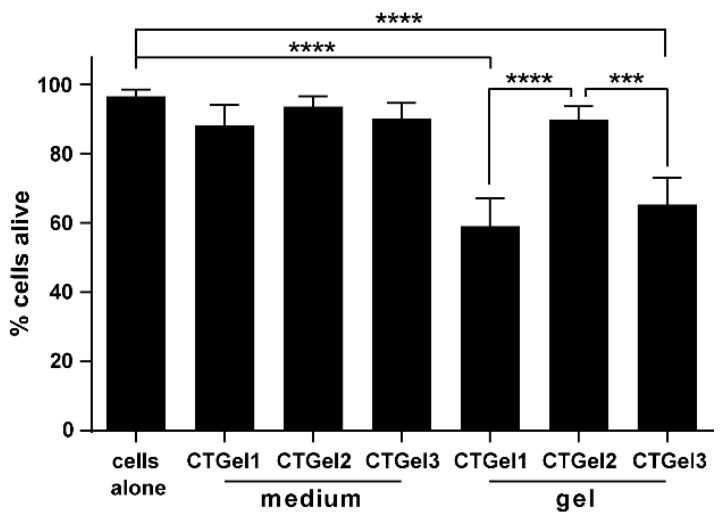

Figure 2. Effect of CTGels on T cell viability. (a) Method of cell encapsulation and culture into CTGels. (b) Contour plots of live/dead assays performed using flow cytometry to analyze cells extracted from the different CTGel formulations. (c) Percentage of cells that were alive in the media and the CTGel at the time of extraction from different formulations at day 5 post-T cell encapsulation. Results are representative of four independent experiments performed in triplicate using three different $T$ cell donors. Graph is representative of average \pm s.d.. ${ }^{* *} P<0.001,{ }^{* * *} P<0.0001$ determined by two-way ANOVA with Tukey's post-test. 
The growth of CTGel-encapsulated T cells was then followed over a 15-day time course, where cell numbers from the medium and from the gel for three different normal donors were determined at every three days post $T$ cell-encapsulation using flow cytometry. Figure $3 a$ represents the gating on $T$ lymphocyte morphology used to generate cell counts from the gel component of the experimental analysis to exclude other particles (i.e., CTGel remnants) also detected by the flow cytometer, but at different sizes) during the analysis of encapsulated cells. Results demonstrate that a stable number of cells was detected from the medium over this time course, with more cells escaping CTGel2 than CTGel1 overall (CTGel3 was not included in testing due to its low gelation rate) (Fig. 3b). Among the T cells isolated from the CTGels, we observed a similar steady-state in cell numbers over time in the CTGel1 formulation. In contrast, cell number increased in the CTGel2 formulation (i.e., from $25.7 \times 10^{6}$ at day 2 to $180.5 \times 10^{6}$ at day 15) (Fig. 3a\&b). Macroscopic examination of the gel color over time was also a clear indicator of $T$ cell growth, with a visually apparent progressive yellowing of CTGel2 over time, relative to the pink color (originally provided by the growth media) maintained by the CTGel1 (Fig. 3c).
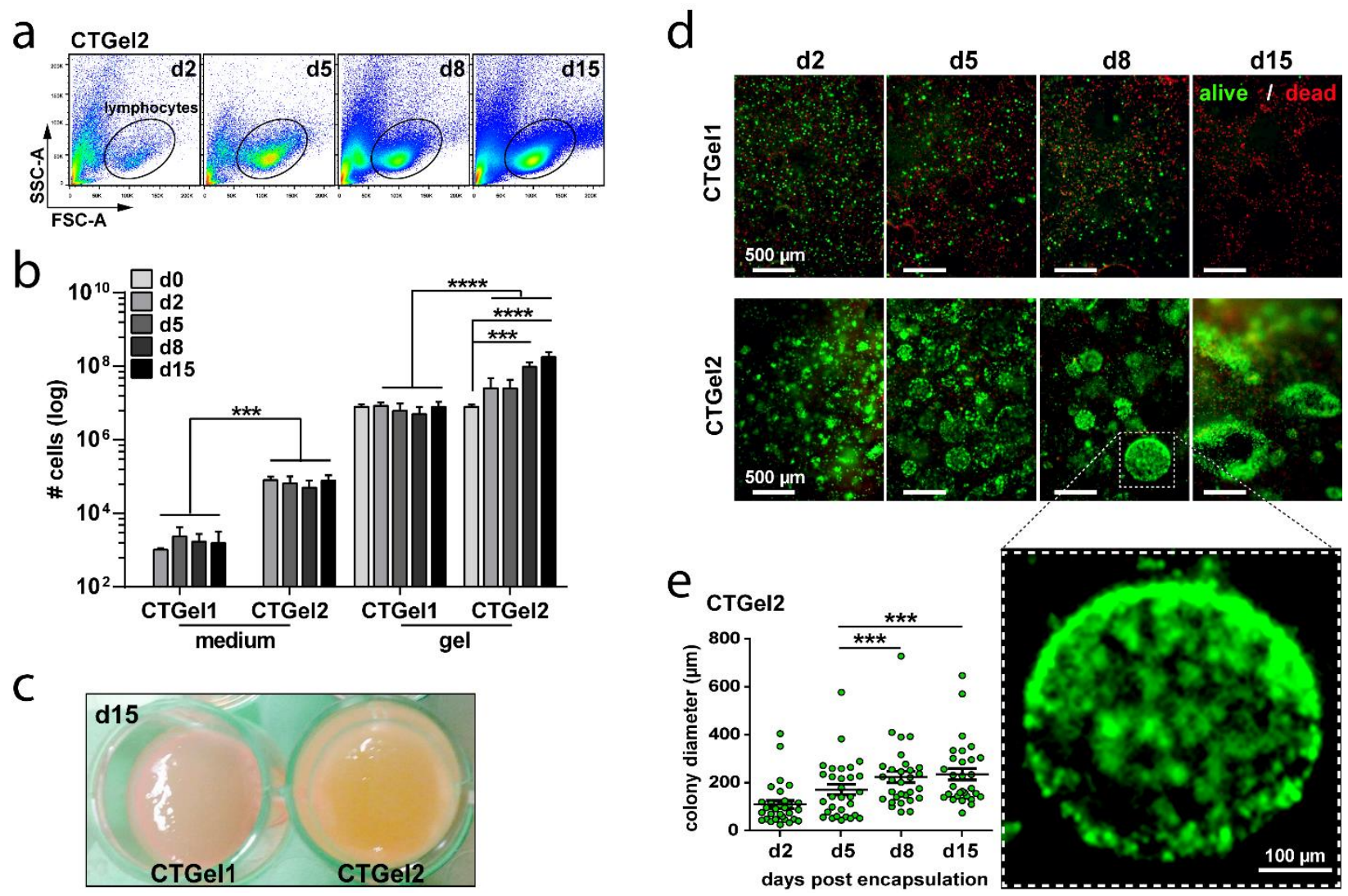

Figure 3. The CTGel formulation promotes cell viability and proliferation of T lymphocytes. (a) Flow cytometry generated scatter plot of live lymphocytes extracted from the CTGel2 formulation over 15 day 
time course, and (b) logarithmic scale of average cell numbers obtained at different time points from the supernatant and from CTGels 1 or 2. (c) Macroscopic images of CTGels 1 and 2 formulations at day 15 post-cell encapsulation (d) Live/dead assay of CTGel 1- or 2-encapsulated cells over 15 day time course experiments (green, alive; red, dead), and (e) accompanying graph to represent average colony diameters over time. For fluorescence experiments, results are representative of five independent experiments performed in triplicate using three different $T$ cell donors. For flow cytometry, results are representative of four independent experiments performed in triplicate using three different $T$ cell donors. Graphs are representative of average \pm s.d.. ${ }^{* * *} P<0.001,{ }^{* * * *} P<0.0001$ determined by two-way (b) or one-way (e) ANOVA with Tukey's post-test.

These results were confirmed by direct visualization of CTGel-encapsulated T cells using live/dead microscopy. Strikingly, the CTGel2 formulation was clearly permissive to the growth of encapsulated T cells that increased in number over time, and colonies that increased in size over time, with diameters spanning as large as $375 \mu \mathrm{m}$ by day 15 (Fig. 3d\&e). With cells much denser at colony edges, these encapsulated colonies represent an intriguing aspect of the 3D culture, and are likely highly dependent on heightened gas diffusion and nutrients exchange throughout this gel formulation as a result of its increased porosity, as observed by SEM (Fig.1d). Differences in cell viability between CTGels 1 and 2 could be explained by their difference in pore size. Pore size varying from $50 \mu \mathrm{m}$ to $500 \mu \mathrm{m}$, as observed for CTGel2, are in accordance with the pre-established pore sizes $(100-500 \mu \mathrm{m})$ that have been correlated with optimal cell seeding, proliferation and migration of cells, and with the diffusion of nutrients throughout gel scaffolds [34-36].

During these experiments, from microscopic examination of the gel using live/dead immunofluorescence, we also observed that the numbers of dead cells remained quite constant over time, and that many of these were localized to the bottom and sides of the gel where it would have been tight contact with the 24 well plates, and where we would expect that there would be the lowest amount of air exchange, or the longest possible time for temperature adjustments, and altogether indicating that the dead cells (represented by red throughout imaging), are likely a population of cells that dies during, or very early after cell encapsulation (Fig. 3d). To confirm that the numbers of dead cells were staying constant over time, we examined our flow cytometry data as we had in Figure $2 b-c$. Analysis revealed that the amount of dead cells detected by flow cytometry remains constant over time, and importantly, that cell viability in CTGel2 remained above $85 \%$ over the 15-day time course experiment (data notshown). Altogether, these results indicate that of the three formulations tested, CTGel2 is best suited for encapsulated T cell viability, proliferation and escape from gels over time, and therefore the remainder of experiments presented herein are those using CTGel2. 


\section{CTGel-encapsulated T cell phenotypes can be influenced from surrounding conditions}

In line with our objective to develop a growing 3D T cell culture that can be injected into the tumor microenvironment and once there, release cells over time in response to its chemical cues and chemoattractants, we evaluated whether surrounding conditions could positively influence the activation state of the encapsulated T cells. We thus performed 15 day time course experiments where cells were encapsulated, and cells and media were again collected over time for analysis as before, but with the provision that the media was replaced with fresh, IL-2 containing medium at day 8 in an effort to demonstrate that IL-2 addition could boost the activation state of the encapsulated $\mathrm{T}$ cells, as demonstrated by increased CD25 expression. As CD25 is the high-affinity IL-2 receptor, and its expression on $\mathrm{T}$ lymphocytes is increased upon activation, it is routinely used in flow cytometry to identify activated T lymphocytes [37]. Figure 4 a depicts the gating strategy applied for the analysis of the flow cytometry results, whereby (from left to right) cells are gated for morphology, then viability, and then for activated $\mathrm{CD}^{+} \mathrm{T}$ cells (i.e., $\mathrm{CD} 3^{+} \mathrm{CD} 25^{+}$). Figure $4 \mathrm{~b} \& \mathrm{c}$ reveals that at day 2, cells from CTGel2 were observed to still be highly activated from their growth in OKT3 + IL-2 containing media prior to encapsulation (26.5\% \pm 6.0$)$, and this activation state was diminished by day $5(7.3 \% \pm 3.5)$. However, a surge of reactivation of the cells was observed to occur following the addition of fresh IL-2 containing media to the culture condition at day 8 , returning them to a high level of activation by day $15(36.1 \% \pm 11.1)$ (Fig. 4b\&c). Altogether, these results demonstrate that the CTGel acts as a cellular support that permits the efficient exchange of cellular nutrients and chemical cues from the surrounding conditions to influence the activation state of the encapsulated T cells.

\section{The CTGel favors the growth of $C D 8^{+} T$ lymphocytes}

Cancer immunotherapy ACT protocols use $\mathrm{CD}^{+} \mathrm{T}$ lymphocytes expanded from resected patient tumors because these are the immune cells best recognized to have an anti-tumor effect and to positively impact patient prognosis [38]. Therefore, we assessed the cellular phenotype of the encapsulated T cells to verify that it was not altered from growth in CTGels.

Fifteen-day time course experiments were performed to determine the phenotype of CTGel2 encapsulated T cells. Figure 5a depicts a portion of the gating strategy used in the analysis of the flow cytometry data; where the full gating strategy was: morphology, singlets, alive, $\mathrm{CD} 3^{+}$, and $\mathrm{CD} 8^{+}$or $\mathrm{CD} 4^{+}$. Results show that after expansion in the CTGel2, $\mathrm{CD} 8^{+} \mathrm{T}$ cells were observed to consistently represent a higher proportion of the $\mathrm{CD}^{+} \mathrm{T}$-cell component relative to $\mathrm{CD} 4^{+} \mathrm{T}$ cells, and this was true for both cells actively growing in the gel and for those escaping the gel (Fig. 5b). Over the 15-day time course, we observed that the proportion of $\mathrm{CD}^{+}$and $\mathrm{CD} 8+\mathrm{T}$ cells remained stable in the media but that the proportion of encapsulated $\mathrm{CD}^{+} \mathrm{T}$ cells was increased over time. As control, we immunophenotyped these cells growing in the medium in absence of CTGel2 to observe that the higher overall proportion of the $\mathrm{CD}^{+} \mathrm{T}$ cell component is indeed a feature of IL-2-mediated $\mathrm{T}$ cell expansion from these different 
PBMC donors rather than an effect on their growth in presence of the gel (Fig. 5b, far right). These results indicate that the CTGel2, under these experimental conditions, is favorable to the proportional growth of $\mathrm{CD}^{+} \mathrm{T}$ cell populations over time, and this exemplifies the potential use of this formulation as a host for the growth of a 3D culture that may have true therapeutic potential against solid tumors.

a

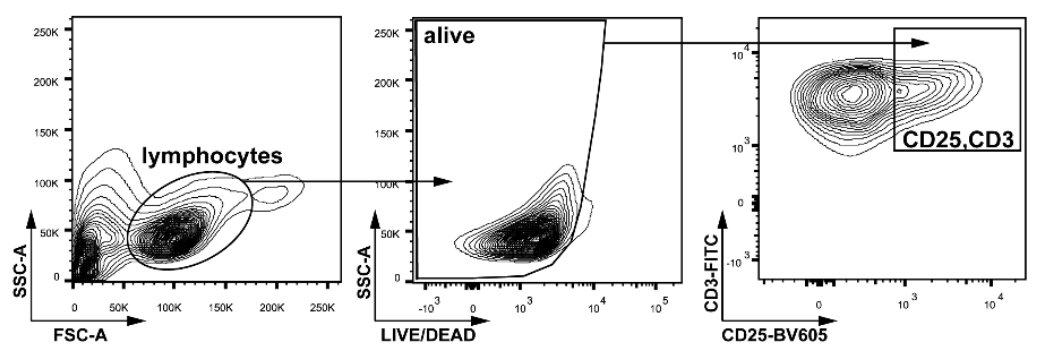

b
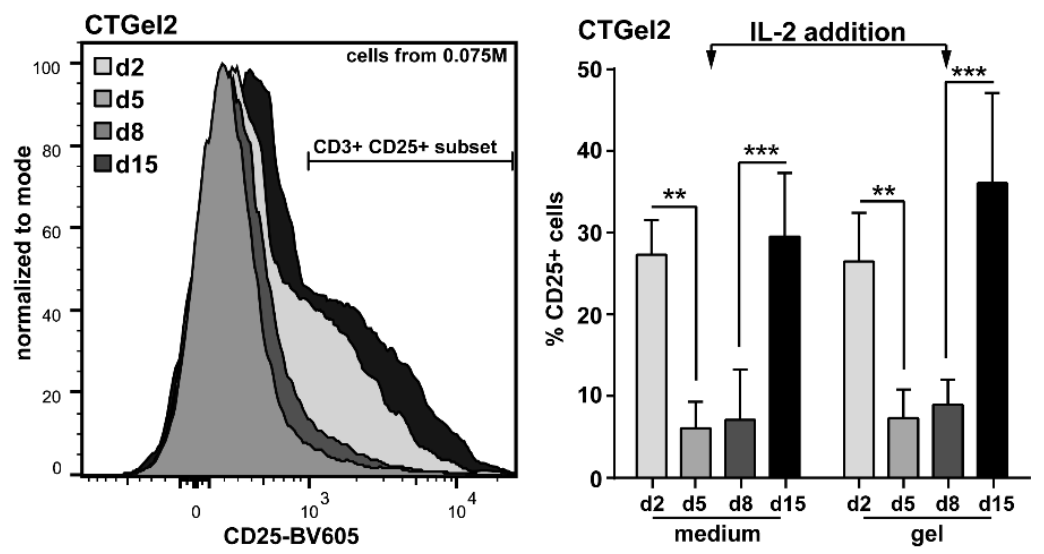

Figure 4. Ambient conditions surrounding the CTGel influence encapsulated T cell activation. (a) Left to right illustration of gating method of flow cytometry data using FlowJo software contour plots for morphology, live/dead staining, and CD3/CD25. (b) FlowJo generated graph (left) of normalized overlays generated by FlowJo showing CD25 expression of CTGel2 extracted T cells at different days postencapsulation. Graph (right) represents percentages of $C D 3^{+} C D 25^{+} T$ cells subsets extracted from the medium and from the CTGel2 at indicated times post-encapsulation, with fresh IL-2 containing medium given at day 8. Results are representative of three independent experiments performed in triplicate using three different normal $T$ cell donors. Bar graphs are representative of average \pm s.d.. ${ }^{* *} P<0.01,{ }^{* * *} P<$ 0.001 determined by one-way ANOVA with Tukey's post-test. 
a
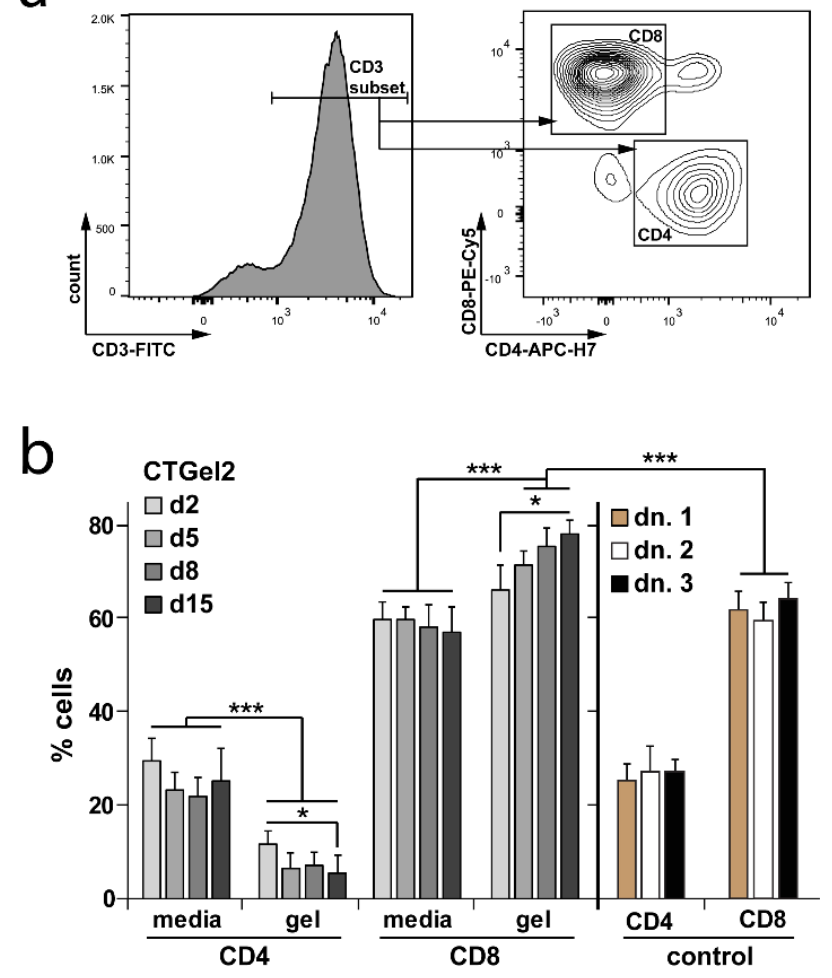

Figure 5. The chitosan-thermogel favors the growth of $\mathrm{CDB}^{+} \mathrm{T}$ lymphocytes. (a) Left to right illustration of part of gating method of flow cytometry data using FlowJo software histogram for $C D 3^{+}$ population gating (left) after morphology/singlets/alive (not shown), for subgating of $C D 8^{+}$and $C D 4^{+}$ populations on right using contour plots. (b) Averaging graph of percent of $C D 3^{+}$cells that are also $C D 8^{+}$ or $\mathrm{CD}^{+}$was determined from cells collected from the media or those extracted from CTGel2 over a 15day time course. Bar graphs on right hand side represents phenotypes from control T cells grown media with no presence of CTGel2 at day 8. Experiments were repeated three times in triplicate using three different $T$ cell donors. Bar graphs are representative of average \pm s.d.. ${ }^{*} P<0.05,{ }^{* *} P<0.01,{ }^{* *} P<$ 0.001 determined by two-way ANOVA with Tukey's post-test.

\section{$T$ cells and TIL escape the chitosan thermogel over time}

Our earlier results demonstrated that encapsulated cells could grow within and also escape the CTGel2 over time. From the observed steady state number of cells in the media, it was uncertain whether cells were truly escaping the gel or simply dividing in the media above the gel (Fig. 3b, medium). Therefore we performed 24-day experiments where every three days post cell-encapsulation the media above the CTGel2 encapsulated cells was completely collected for analysis using flow cytometry and was replaced with fresh media. We used the same three different normal donors (i.e., dn. 1, 2 and 3) and we also used TIL expanded from a kidney cancer patient tumor (i.e., k. pt. TIL\#1) (Figure 6a). Control conditions using the CTGel1 were also used to observe that this gel did not allow a high proportion of cells to escape the 
gel, as was observed from earlier experiments (data not shown). Over these longer time courses, the weights of CTGels were also recorded to verify that no loss in gel integrity was occurring. Figure 6a results demonstrate that indeed, cells are continuously being released from the gel over time. From an initial encapsulation of $4 \times 10^{6}$ cells per $0.5 \mathrm{~mL}$ of CTGel2, as many as $1.8 \times 10^{5} \mathrm{~T}$ cells from normal donor 2 (i.e., dn. 2) were observed to escape from the gel over a period of 24 days. We expect the number of cells escaping the gel could be accelerated when encapsulated cells face more strongly stimulating inflammatory and chemoattractant signatures emanating from an adjacent tumor microenvironment [3941].

a

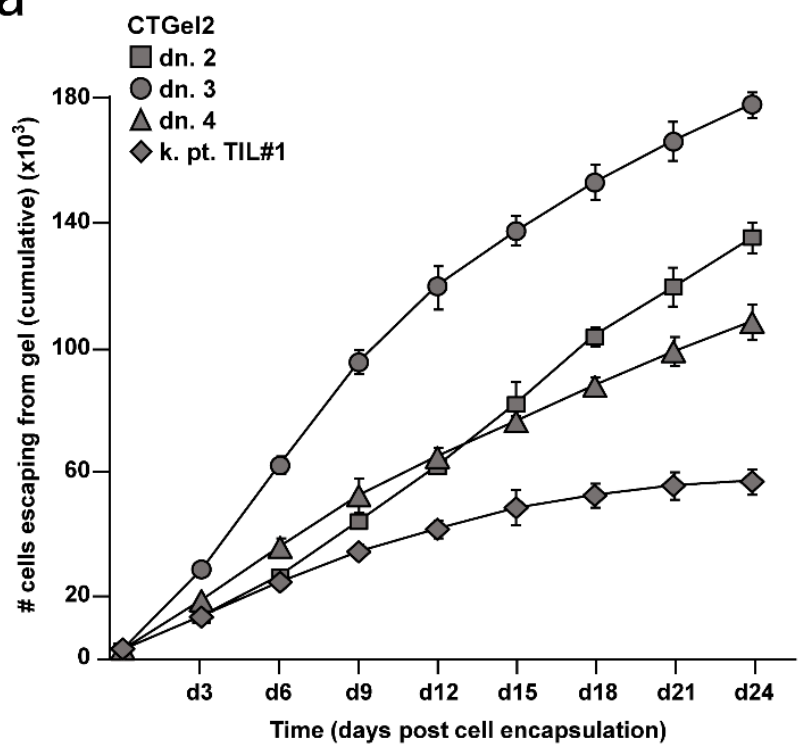

b

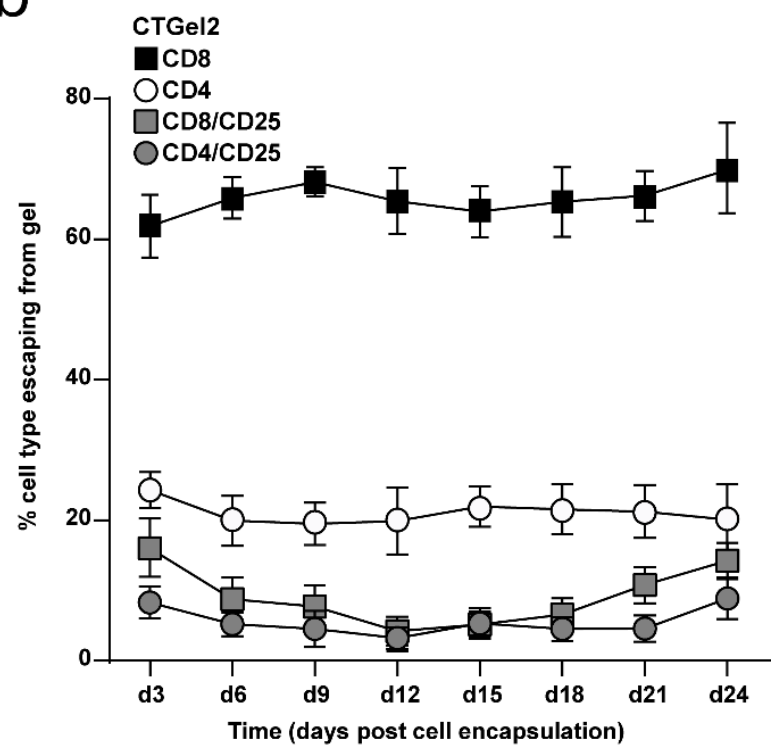

Figure 6. T cells and TIL escape the CTGel2 over time. (a) Cumulative graph of average numbers of cells escaping CTGel2 over a 24-day time course for T cells from normal donors (dn.), and for TIL expanded from a cCRCC kidney tumour (k. pt. TIL\#1). (b) Graph representing percentages of $C D 3^{+} T$ cells that are also positive for $C D 8^{+}, C D 4^{+}$and $C D 25^{+}$from cells collected from the medium over a 24-day time course experiments. Results are representative of experiments performed in triplicate.

In these experiments, we also immunophenotyped the cells using flow cytometry to observe their CD4 ${ }^{+}$ and $\mathrm{CD}^{+}$proportions, along with their $\mathrm{CD}^{2} 5^{+}$activation status. We gated on morphology, singlets, alive, and CD3 to then record percentages of $\mathrm{T}$ cells that were either $\mathrm{CD} 4^{+}$or $\mathrm{CD} 8^{+}$, and we then gated onto these to record the percentages of $\mathrm{CD}^{+}$and $\mathrm{CD} 8^{+} \mathrm{T}$ cells that were also activated based on CD25 positivity. As we saw in earlier experiments, we here have again observed that the CTGel2 is more permissive to the growth of $\mathrm{CD}^{+} \mathrm{T}$ cells (Figure $6 \mathrm{~b}$ ). In addition, in the analysis of CD25 expression, we observed that it is more highly expressed by $\mathrm{CD} 8^{+} \mathrm{T}$ cells at day 3 , is incrementally decreased until day 12 , and then has a resurgence in expression until day 24 to levels similar to those at the time of cell 
encapsulation. In accordance with the finding that the $\mathrm{CD} 4^{+} \mathrm{T}$ cells do not have as high of an increase in CD25, and that their percentages are not increasing with time as are those of CD8 ${ }^{+} \mathrm{T}$ cells (known to be more responsive to the IL-2 from the surrounding media being continuously replenished), this finding substantiates the skewing of the $\mathrm{CD}^{+} / \mathrm{CD} 4^{+}$population ratio under these experimental conditions. Altogether, these results indicate that the CTGel2 allows the continued escape of cells over time, and that this hydrogel formulation positively influences the phenotype and activation state of $\mathrm{CD} 8^{+} \mathrm{T}$ cells.

\section{Encapsulated TIL are activated and escape in response to tumor fragments}

With the knowledge that T cells as well as TIL could grow in and escape the CTGel2 over time, and that the activation state of encapsulated T cells was influenced by surrounding conditions, we wondered if encapsulated TIL could also respond to tumors. We therefore applied a transwell system in order to challenge the CTGel2 encapsulated TIL with tumor fragments. Here, TIL expanded from resected ccRCC kidney tumors were CFSE labeled and encapsulated in CTGel2 before being poured in the transwell insert separating the encapsulated TIL from the tumor fragments placed in the bottom of the 24-well culture dishes below (Fig. 7a, illustration). The CFSE cell permeable fluorescent staining dye is covalently coupled to intracellular lysine residues, and is stable in cells over long periods of time. Its cellderived fluorescence signal is diminished by each cell division, allowing the tracking of the labeled cells and their proliferation. Here, the CFSE labeling was important for both the tracking of CTGel encapsulated TIL proliferation, and the discerning of these from de novo expanding TIL from the living tumor fragments below. We collected all cells from the gel within the insert, and also from the cell culture dish medium below for analysis using flow cytometry five days following cell encapsulation. 
a

$\square$ TIL from med

$\square$ TIL from med (+ frag)

$\square$ TIL from gel

$\square$ TIL from gel (+ frag)

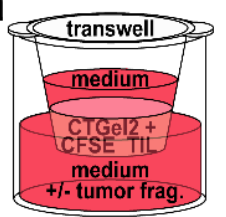

b
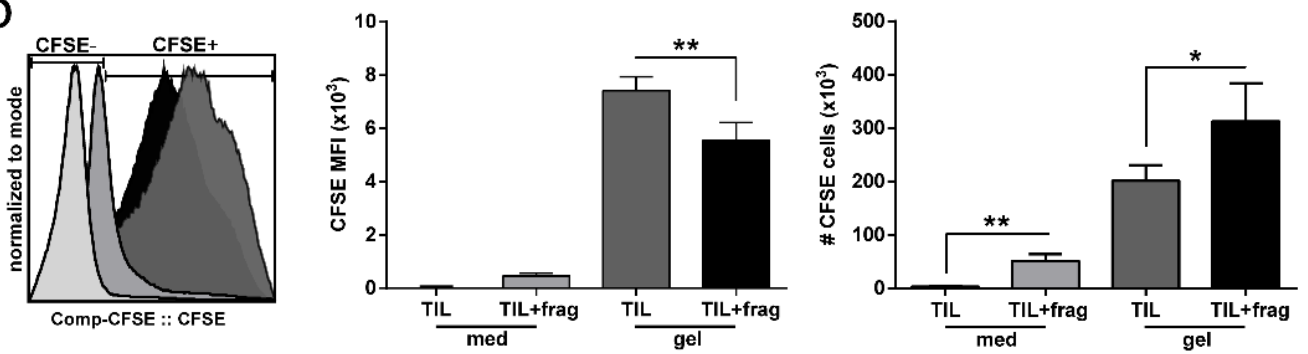

C
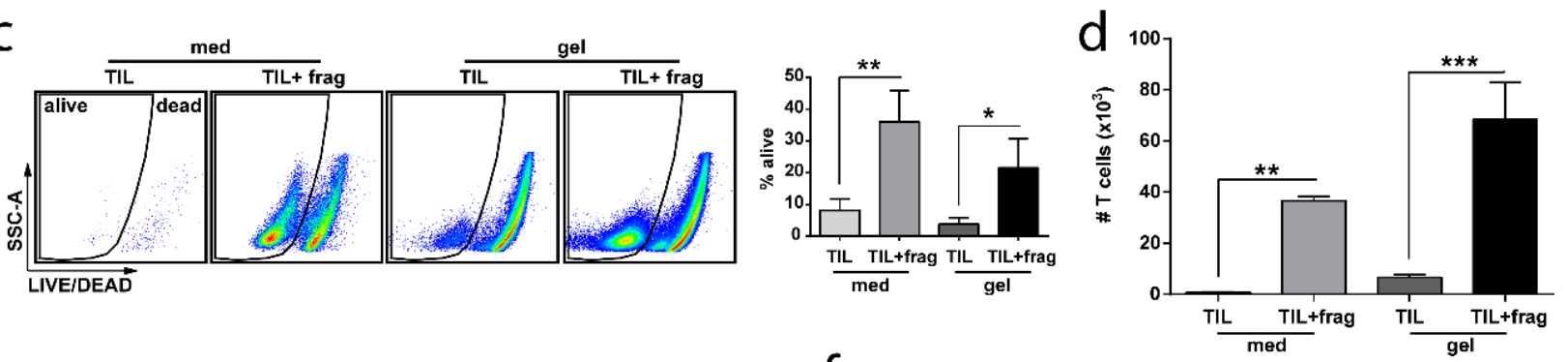

e

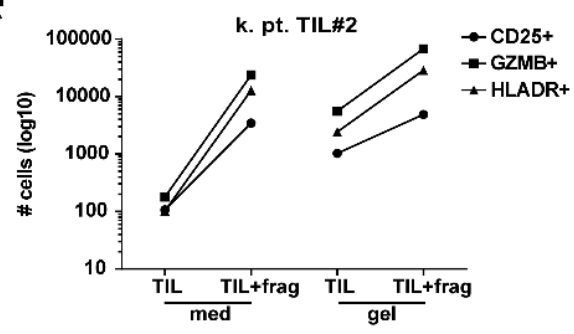

f
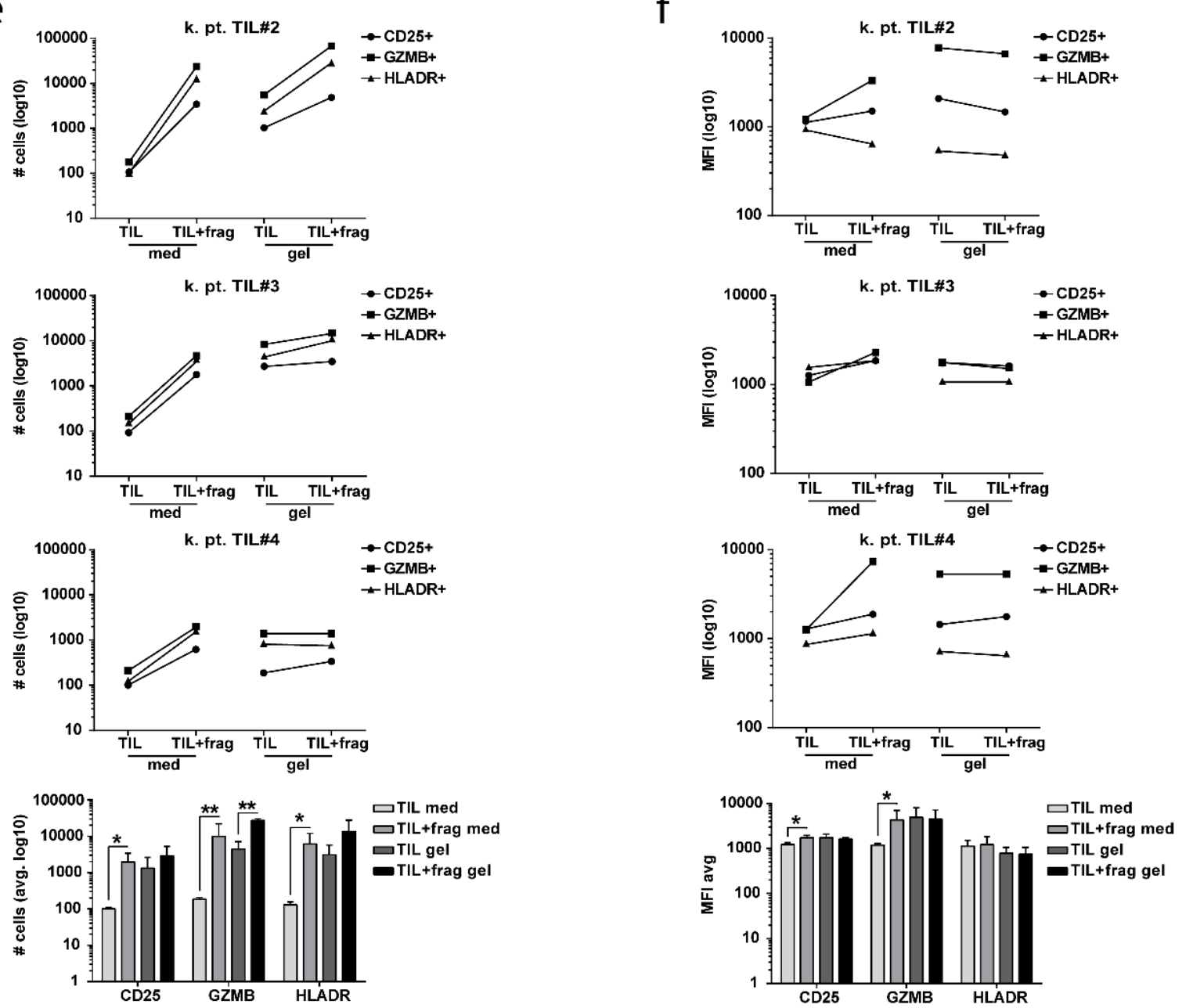

Figure 7. Renal cancer tumor TIL encapsulated in CTGel2 proliferate and are activated in response to tumor fragments. (a) Depiction of transwell system and legend for all panels in figure. (b) CFSE MFI normalized histogram, changes in CFSE MFI, and changes in numbers of CFSE positive TIL in response 
to tumor fragments. (c) Live/dead flow cytometry dot plot demonstrating increased number of live TIL in response to tumor fragments (left) with averaging graph (right). (d) Increased numbers of TIL in response to tumor fragments. Numbers of TIL positive (e), and TIL MFI (f) for activation and cytotoxicity markers (CD25, HLA-DR, GZMB, respectively), with averaging graphs below. med: cells from medium; gel: cells from gel; +frag: +tumor fragments in bottom well; k. pt. TIL, ccRCC kidney cancer patient tumor expanded TIL. Graphs are representative of avg. \pm s.d. . ${ }^{\star} P<0.05$, ${ }^{* *} P<0.01,{ }^{\star * *} P<0.001$ determined by one-way (a-c) or two-way (d-e) ANOVA with Tukey's post-test.

We first analyzed cells according to their CFSE-fluorescence levels (Fig. 7b). Here, we observed the presence of CFSE-positive cells in the cell culture dish medium below in conditions where tumor fragments were also present (mean fluorescence intensity (MFI) $615 \pm 114$ ), indicating that the tumors stimulated the escape of CTGel-encapsulated CFSE positive TIL. In the analysis of encapsulated cells, relative to conditions where no tumor fragments was present (MFI 7417 \pm 521 ), we observed a decrease in CFSE signal from the tumor fragment challenge conditions (MFI 5544 \pm 677 ), indicating that the presence of tumor fragments induce an increase in TIL cell division, and thus a diminishment in number of detectable CFSE molecules per cell (Fig. 7b, middle graph). Indeed, an increase in the numbers of CFSE positive encapsulated cells in tumor fragment-positive conditions $(201.48 \mathrm{~K} \pm 29$ vs $312.89 \mathrm{~K} \pm 76)$ is inversely correlated with their reduced CFSE signals as a result of increased cell division (Fig. $\mathbf{7 b}$, right graph). Together, these results demonstrate that the tumor fragments caused an increase in TIL proliferation and migration towards the tumor environment.

Using live/dead staining and flow cytometry, gating on $\mathrm{CFSE}^{+} /$alive ${ }^{+}$cells provided evidence that the total numbers of TIL that were alive in both the medium and the CTGel2 was > 4-fold higher in presence if tumor fragments (Fig. 7c, dot plot and graph). By then gating on CD3, we observed that the presence of tumor fragments caused an increase in the number of TIL in both the CTGel2 and the medium in the wells below (i.e.., from $6640 \pm 994$ to $68385 \pm 14497$ in gel, and from $124 \pm 21$ to $36660 \pm 1590$ in medium) from an initial $2 \times 10^{6} \mathrm{TIL}$ encapsulated in $0.25 \mathrm{~mL}$ of CTGel2. Altogether, these results indicate that the presence of the tumors cause increases in TIL survival, growth, escape, and migration (Fig. 7d).

Finally, to verify that the cells growing and escaping in response to tumors where those that might be primed against the tumor, we analyzed cells that were $\mathrm{CFSE}{ }^{+} / \mathrm{CD}^{+}$and also positive for early (CD25) and late (HLA-DR) activation, and cytotoxic Granzyme B (GZMB) markers [42-44]. Here, we analyzed both the numbers of cells positive for, and cell MFI for these markers (Fig. 7e\&f). Across these patients, we observed that a consistently higher number of TIL from the medium were positive for these markers in conditions where the tumor fragment was present (Fig. 7e). As for TIL that had been CTGel2encapsulated, only GZMB expression was significantly increased in conditions where tumor fragments 
were present (Fig. 7e). This indicates that in this system, TIL become more activated and potentially cytotoxic in response to tumor fragments as they come into closer contact with them. The MFI of CD25 and GZMB were also increased in the TIL analyzed from the medium, whereas no change in the MFI of these markers was observed for TIL extracted from gels (Fig. 7f). Altogether, these results demonstrate that in response to the tumor fragments they were originally expanded from, CTGel2-encapsulated TIL will increase in their proliferation and migration, and retain their capacities to express activation and cytotoxic markers.

\section{Antigen-specific encapsulated T cells migrate to and kill cancer cells}

We then addressed whether the observed increases in activation and cytotoxic markers for encapsulated TIL were the result of their being challenged by their cognate target cancer cells. In addition, we wished to develop a robust assay for the in vitro and in vivo testing and inferring of the ability of encapsulated T cells to reduce tumor cell burden. Therefore, we adjoined the CTGel-transwell methodology to a common in vitro recognition assay, where a T cell clone specific to a melanoma antigen (gp100) presented by HLAA2 was encapsulated in the CTGel2 poured in the transwell insert above, and the CFSE-labeled specific target melanoma cancer cells (SK23-mel and 624-mel, both $\mathrm{HLA}-\mathrm{A}_{2}{ }^{+} / \mathrm{gp} 100^{+}$) were seeded in the culture dishes below (Fig. 8a). The HLA-A2 $/ g p 100^{+} 586-\mathrm{mel}$ and breast cancer cell line MDA231 (HLA$\mathrm{A}^{+} / \mathrm{gp} 100^{\circ}$ ) were used as negative controls. In this case, as CFSE is covalently bound, and thus retained by dead cells, its use would help us to identify target cells positive for apoptosis marker AnnexinV.

Cells were collected from the bottom well of the culture dish five days later, and flow cytometry was used to analyze the anti-gp100 T cells by first gating on lymphocytes/singlets/alive/CD8 to then analyze them for activation marker CD25, Th1 cytokine tumor necrosis factor-alpha (TNF- $\alpha$ ), and cytotoxic markers Perforin-1 (PRF1) and GZMB (Fig. 8b). From these experiments, we consistently observed an increase in expression of these markers in the presence of their target cancer cells (and especially SK23-mel) (Fig. $\mathbf{8 b \& d}$ ). Flow cytometry was also used to analyze the AnnexinV content of the CFSE-labeled cancer cells, where we observed an increase in this marker in the target cancer cell lines 624-mel and SK23-mel, indicating that the anti-gp100 T cells that had escaped the CTGel2 and had migrated down to the bottom of the transwell system had also successfully killed a proportion of their target cells (Fig. 8c\&d). Finally, ELISA was used to calculate the concentration of Th1 cytokine interferon gamma (IFNY) from the cell supernatant, and revealed an increase in its expression in conditions where the target cancer cells were present, and which represents another readout of cancer cell killing efficacy of the encapsulated $T$ cells (Fig. 8e). These results indicate that the CTGel2 encapsulated T cells escape the gel and migrate towards their target cancer cells, where they are activated, produce Th1 cytokine and cytotoxic markers, and also actually kill their target cells. This provides evidence that encapsulated $T$ cells will retain their potential to kill the CTGel2-neighboring cancer cells of the tumor microenvironment. 
a
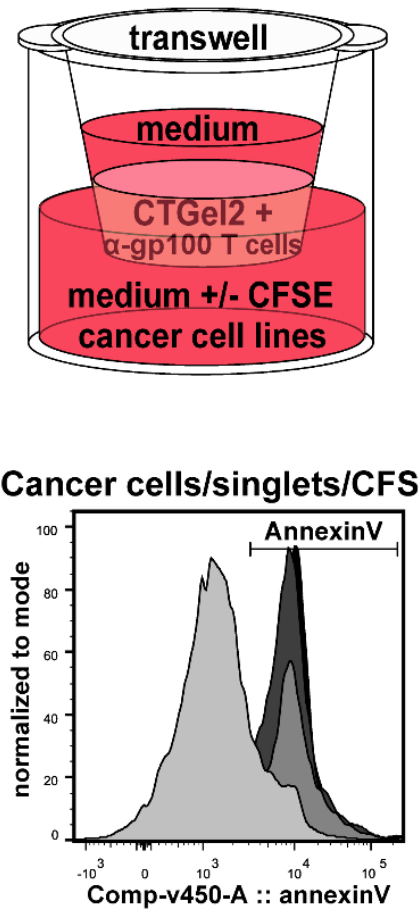

C Cancer cells/singlets/CFSEI

b

Lymphocytes/singlets/alive/CD8/
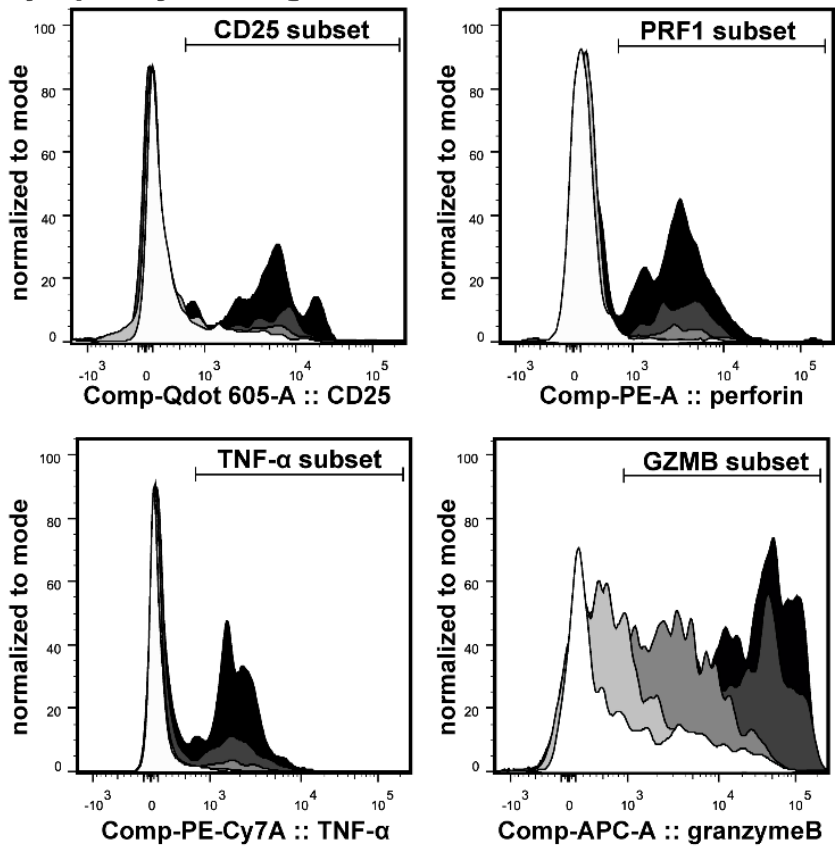

d

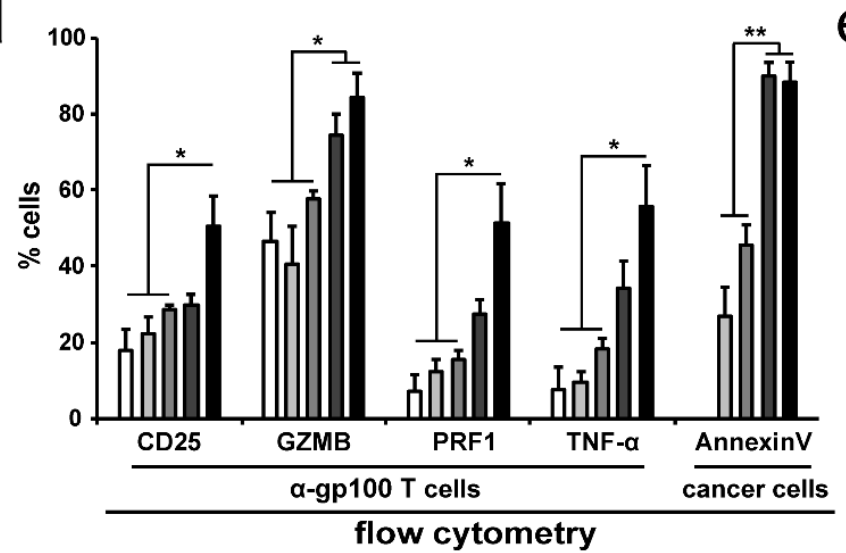

\section{Legend}

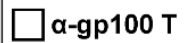

$\square$ a-gp100 T + MDA231

$\square$ a-gp100 T + 586-mel

$\square$ a-gp100 T + 624-mel

a-gp100 T + SK23-mel

Figure 8. CTGel2-transwell-mediated recognition/killing assay using $\alpha$-gp100 $T$ cell clone and melanoma cancer cell lines. (a) Depiction of transwell system, illustrating how a-gp100 T cell clones were encapsulated in CTGel2 within transwells and CFSE labeled cancer cell lines were seeded at the bottom within the culture dish wells. Five days later, cells are collected from the medium at the bottoms of culture dish wells, and were split into two fractions for analysis. (b) Fraction one was analyzed using flow cytometry with gating strategy: lymphocytes (morphology)/singlets/alive/CD8, and then either CD25, PRF1, TNF- $\alpha$ or GZMB. (c) Fraction two was analyzed using gating strategy: cancer cells (morphology)/singlets/CFSE /AnnexinV. (b-c) FlowJo was used to generate normalized to mode displays of MFIs. (d) Percent cells expressing markers of interest are depicted in averaging graphs representative of two independent experiments preformed in triplicate. (e) Left, ELISA was used to assess the concentration of IFN-y from the cell supernatants; right, legend provided for all figure panels. Bar graphs 
are representative of avg. \pm s.d.. ${ }^{*} P<0.05$, ${ }^{* *} P<0.01$, ${ }^{* *} P<0.001$ determined by two-way ANOVA with Tukey's post-test.

To date, little progress has been made towards the development of 3D scaffolds for $T$ cell delivery or recruitment for immunotherapeutic strategies [45-49]. Stephan et al. have designed an alginate scaffold able to release $\mathrm{T}$ cell over time for the treatment of inaccessible tumors or cancer recurrence [45]. These scaffolds however, require open surgery for their implantation [45, 46]. Moreover, since alginate is not naturally enzymatically degraded in mammals, months may pass before they are completely removed from their original sites of implantation [50]. An injectable polymer made of chitosan covalently grafted with polyethylene glycol has also been recently developed by Tsao et al. for local T cell administration to combat glioblastoma recurrence following tumor excision [47]. The authors have shown that $T$ cells seeded at the surface of the materials are able to migrate through the hydrogel and keep their cytotoxic functionality against tumor cell lines for over four days. The mechanical properties and compatibility for cell encapsulation were however not demonstrated for their gel formulation, and there was little evidence that cells could proliferate in these gels long term.

The present work achieves very significant progress towards a clinically effective strategy for use of injectable 3D T cell cultures. Indeed, we have shown that T cells can be directly encapsulated and remain viable and effective for at least 24 days in the new chitosan thermogel formulation tested due to its $\mathrm{pH}$ and osmolalities being at physiological range, and to the absence of crosslinking agent and organic solvents. The mechanical and thermosensitive properties of this hydrogel ensure easy injectability and rapid gelation at body temperature, and the forming a scaffold that will degrade over time, thus preventing risks of long-term continuation of $\mathrm{T}$ cell proliferation and any possible associated side-effects. The rate of biodegradation of chitosan hydrogels is known to be influenced by the degree of chitosan deacetylation $[51,52]$, which was here chosen to be at $94 \%$ to ensure that gel resistance can last for at least several weeks in vivo. In vivo testing including biodegradation rates is the subject of future experiments.

\section{Conclusion}

A new injectable biodegradable scaffold for the delivery of living T lymphocyte cultures was developed. Its thermosensitivity and mechanical properties ensure easy injectability and rapid gelation. In vitro models involving expanded TIL have clearly demonstrated that these cells can survive, proliferate and be attracted from the hydrogel by the chemical signature of the tumor microenvironment. Moreover, by using established killing assays, we have provided strong evidence that $T$ cells remain cytotoxically functional after encapsulation. Our evidence supports the notion that the CTGel2 presents itself as a superior cellular support towards the development of 3D TIL injectable cultures that will allow the delivery of minimal numbers of tumor-expanded TIL for their local response and attack of the nearby tumor cells. 


\section{Acknowledgements:}

We thank Jean-Baptiste Lattouf and Louise Rousseau (CHUM Kidney cancer biobank) for her assistance with patient samples, Guillaume Chouinard (CRCHUM Cellular imaging facility) for technical support and advice, Genevieve Lauzon (CRCHUM Animal facility) for her assistance with CTGel injection into rats, and Laïla-Aïcha Hanafi, David Possamaï and Stéphanie Lepage for their assistance with killing assays and ELISAs. This work was supported by the Canadian Research Chair (CRC) in biomaterials and endovascular implants (Sophie Lerouge) and funding from the Canadian Cancer Society Research Institute (CCSRI) and the Kidney Foundation of Canada to Réjean Lapointe. Caroline Ceccaldi acknowledges FRQ-S scholarship and Elias Assaad acknowledges FRQ-NT scholarship.

\section{References}

[1] Restifo NP, Dudley ME, Rosenberg SA. Adoptive immunotherapy for cancer: harnessing the T cell response. Nature reviews Immunology. 2012;12:269-81.

[2] Joseph RW, Peddareddigari VR, Liu P, Miller PW, Overwijk WW, Bekele NB, et al. Impact of clinical and pathologic features on tumor-infiltrating lymphocyte expansion from surgically excised melanoma metastases for adoptive T-cell therapy. Clinical cancer research : an official journal of the American Association for Cancer Research. 2011;17:4882-91.

[3] Wu R, Forget MA, Chacon J, Bernatchez C, Haymaker C, Chen JQ, et al. Adoptive T-cell therapy using autologous tumor-infiltrating lymphocytes for metastatic melanoma: current status and future outlook. Cancer journal. 2012;18:160-75.

[4] Besser MJ, Shapira-Frommer R, Treves AJ, Zippel D, Itzhaki O, Schallmach E, et al. Minimally cultured or selected autologous tumor-infiltrating lymphocytes after a lympho-depleting chemotherapy regimen in metastatic melanoma patients. Journal of immunotherapy. 2009;32:415-23.

[5] Tran KQ, Zhou J, Durflinger KH, Langhan MM, Shelton TE, Wunderlich JR, et al. Minimally cultured tumor-infiltrating lymphocytes display optimal characteristics for adoptive cell therapy. Journal of immunotherapy. 2008;31:742-51.

[6] Goff SL, Smith FO, Klapper JA, Sherry R, Wunderlich JR, Steinberg SM, et al. Tumor infiltrating lymphocyte therapy for metastatic melanoma: analysis of tumors resected for TIL. Journal of immunotherapy. 2010;33:840-7.

[7] Shapira-Frommer R, Schachter J. Adoptive immunotherapy of advanced melanoma. Current treatment options in oncology. 2012;13:340-53.

[8] Prieto PA, Durflinger KH, Wunderlich JR, Rosenberg SA, Dudley ME. Enrichment of CD8+ cells from melanoma tumor-infiltrating lymphocyte cultures reveals tumor reactivity for use in adoptive cell therapy. Journal of immunotherapy. 2010;33:547-56.

[9] Itzhaki O, Hovav E, Ziporen Y, Levy D, Kubi A, Zikich D, et al. Establishment and large-scale expansion of minimally cultured "young" tumor infiltrating lymphocytes for adoptive transfer therapy. Journal of immunotherapy. 2011;34:212-20.

[10] Dudley ME, Gross CA, Langhan MM, Garcia MR, Sherry RM, Yang JC, et al. CD8+ enriched "young" tumor infiltrating lymphocytes can mediate regression of metastatic melanoma. Clinical cancer research : an official journal of the American Association for Cancer Research. 2010;16:6122-31.

[11] Griffith KD, Read EJ, Carrasquillo JA, Carter CS, Yang JC, Fisher B, et al. In vivo distribution of adoptively transferred indium-111-labeled tumor infiltrating lymphocytes and peripheral blood lymphocytes in patients with metastatic melanoma. Journal of the National Cancer Institute. 1989;81:1709-17.

[12] Fisher B, Packard BS, Read EJ, Carrasquillo JA, Carter CS, Topalian SL, et al. Tumor localization of adoptively transferred indium-111 labeled tumor infiltrating lymphocytes in patients with metastatic 
melanoma. Journal of clinical oncology : official journal of the American Society of Clinical Oncology. 1989;7:250-61.

[13] Hershkovitz L, Schachter J, Treves AJ, Besser MJ. Focus on adoptive T cell transfer trials in melanoma. Clinical \& developmental immunology. 2010;2010:260267.

[14] Dieu-Nosjean MC, Goc J, Giraldo NA, Sautes-Fridman C, Fridman WH. Tertiary lymphoid structures in cancer and beyond. Trends in immunology. 2014;35:571-80.

[15] Martinet L, Garrido I, Girard JP. Tumor high endothelial venules (HEVs) predict lymphocyte infiltration and favorable prognosis in breast cancer. Oncoimmunology. 2012;1:789-90.

[16] Dieu-Nosjean MC, Antoine M, Danel C, Heudes D, Wislez M, Poulot V, et al. Long-term survival for patients with non-small-cell lung cancer with intratumoral lymphoid structures. Journal of clinical oncology : official journal of the American Society of Clinical Oncology. 2008;26:4410-7.

[17] Goc J, Fridman WH, Hammond SA, Sautes-Fridman C, Dieu-Nosjean MC. Tertiary lymphoid structures in human lung cancers, a new driver of antitumor immune responses. Oncoimmunology. 2014;3:e28976.

[18] Coppola D, Nebozhyn M, Khalil F, Dai H, Yeatman T, Loboda A, et al. Unique ectopic lymph nodelike structures present in human primary colorectal carcinoma are identified by immune gene array profiling. The American journal of pathology. 2011;179:37-45.

[19] Wirsing AM, Rikardsen OG, Steigen SE, Uhlin-Hansen L, Hadler-Olsen E. Characterisation and prognostic value of tertiary lymphoid structures in oral squamous cell carcinoma. BMC clinical pathology. 2014;14:38.

[20] Nielsen JS, Nelson BH. Tumor-infiltrating B cells and T cells: Working together to promote patient survival. Oncoimmunology. 2012;1:1623-5.

[21] Rhee J, Park OK, Lee A, Yang DH, Park K. Glycol Chitosan-Based Fluorescent Theranostic Nanoagents for Cancer Therapy. Marine drugs. 2014;12:6038-57.

[22] Suh JK, Matthew HW. Application of chitosan-based polysaccharide biomaterials in cartilage tissue engineering: a review. Biomaterials. 2000;21:2589-98.

[23] Shukla SK, Mishra AK, Arotiba OA, Mamba BB. Chitosan-based nanomaterials: a state-of-the-art review. International journal of biological macromolecules. 2013;59:46-58.

[24] Chenite A, Chaput C, Wang D, Combes C, Buschmann MD, Hoemann CD, et al. Novel injectable neutral solutions of chitosan form biodegradable gels in situ. Biomaterials. 2000;21:2155-61.

[25] Ahmadi R, de Bruijn JD. Biocompatibility and gelation of chitosan-glycerol phosphate hydrogels. Journal of biomedical materials research Part A. 2008;86:824-32.

[26] Assaad E, Maire M, Lerouge S. Injectable thermosensitive chitosan hydrogels with controlled gelation kinetics and enhanced mechanical resistance. Carbohydrate polymers. 2015;130:87-96.

[27] Liu L, Tang X, Wang Y, Guo S. Smart gelation of chitosan solution in the presence of NaHCO3 for injectable drug delivery system. International journal of pharmaceutics. 2011;414:6-15.

[28] Huang Z, Yu B, Feng Q, Li S. Modification of an injectable chitosan scaffold by blending with $\mathrm{NaHCO} 3$ to improve cytocompatibility. Polymers and Polymer Composites. 2011;19:781-7.

[29] Winter HH CF. Analysis of linear viscoelasticity of a crosslinking polymer at the gel point. Journal of Rheology. 1986;30:367.

[30] Riddell SR, Greenberg PD. The use of anti-CD3 and anti-CD28 monoclonal antibodies to clone and expand human antigen-specific T cells. Journal of immunological methods. 1990;128:189-201.

[31] Klapper JA, Thomasian AA, Smith DM, Gorgas GC, Wunderlich JR, Smith FO, et al. Single-pass, closed-system rapid expansion of lymphocyte cultures for adoptive cell therapy. Journal of immunological methods. 2009;345:90-9.

[32] Dudley ME, Wunderlich JR, Shelton TE, Even J, Rosenberg SA. Generation of tumor-infiltrating lymphocyte cultures for use in adoptive transfer therapy for melanoma patients. Journal of immunotherapy. 2003;26:332-42.

[33] Pelletier S, Tanguay S, Lee S, Gunaratnam L, Arbour N, Lapointe R. TGF-alpha as a candidate tumor antigen for renal cell carcinomas. Cancer immunology, immunotherapy : Cll. 2009;58:1207-18.

[34] Pisanti P, Yeatts AB, Cardea S, Fisher JP, Reverchon E. Tubular perfusion system culture of human mesenchymal stem cells on poly-L-lactic acid scaffolds produced using a supercritical carbon dioxideassisted process. Journal of biomedical materials research Part A. 2012;100:2563-72.

[35] Ikada Y. Challenges in tissue engineering. Journal of the Royal Society, Interface / the Royal Society. 2006;3:589-601. 
[36] Mikos AG, Sarakinos G, Lyman MD, Ingber DE, Vacanti JP, Langer R. Prevascularization of porous biodegradable polymers. Biotechnology and bioengineering. 1993;42:716-23.

[37] Boyman O, Sprent J. The role of interleukin-2 during homeostasis and activation of the immune system. Nature reviews Immunology. 2012;12:180-90.

[38] Fridman WH, Pages F, Sautes-Fridman C, Galon J. The immune contexture in human tumours: impact on clinical outcome. Nature reviews Cancer. 2012;12:298-306.

[39] Zhou J, Xiang Y, Yoshimura T, Chen K, Gong W, Huang J, et al. The role of chemoattractant receptors in shaping the tumor microenvironment. BioMed research international. 2014;2014:751392. [40] Gajewski TF, Woo SR, Zha Y, Spaapen R, Zheng Y, Corrales L, et al. Cancer immunotherapy strategies based on overcoming barriers within the tumor microenvironment. Current opinion in immunology. 2013;25:268-76.

[41] Sharma RK, Chheda ZS, Jala VR, Haribabu B. Regulation of cytotoxic T-Lymphocyte trafficking to tumors by chemoattractants: implications for immunotherapy. Expert review of vaccines. 2015;14:537-49. [42] Santin AD, Ravaggi A, Bellone S, Pecorelli S, Cannon M, Parham GP, et al. Tumor-infiltrating lymphocytes contain higher numbers of type 1 cytokine expressors and $\mathrm{DR}+\mathrm{T}$ cells compared with lymphocytes from tumor draining lymph nodes and peripheral blood in patients with cancer of the uterine cervix. Gynecologic oncology. 2001;81:424-32.

[43] Schleypen JS, Baur N, Kammerer R, Nelson PJ, Rohrmann K, Grone EF, et al. Cytotoxic markers and frequency predict functional capacity of natural killer cells infiltrating renal cell carcinoma. Clinical cancer research : an official journal of the American Association for Cancer Research. 2006;12:718-25. [44] Grabenbauer GG, Lahmer G, Distel L, Niedobitek G. Tumor-infiltrating cytotoxic T cells but not regulatory $T$ cells predict outcome in anal squamous cell carcinoma. Clinical cancer research : an official journal of the American Association for Cancer Research. 2006;12:3355-60.

[45] Stephan SB, Taber AM, Jileaeva I, Pegues EP, Sentman CL, Stephan MT. Biopolymer implants enhance the efficacy of adoptive T-cell therapy. Nature biotechnology. 2015;33:97-101.

[46] Stachowiak AN, Irvine DJ. Inverse opal hydrogel-collagen composite scaffolds as a supportive microenvironment for immune cell migration. Journal of biomedical materials research Part $A$. 2008;85:815-28.

[47] Tsao CT, Kievit FM, Ravanpay A, Erickson AE, Jensen MC, Ellenbogen RG, et al. Thermoreversible poly(ethylene glycol)-g-chitosan hydrogel as a therapeutic $\mathrm{T}$ lymphocyte depot for localized glioblastoma immunotherapy. Biomacromolecules. 2014;15:2656-62.

[48] Schor SL, Allen TD, Winn B. Lymphocyte migration into three-dimensional collagen matrices: a quantitative study. The Journal of cell biology. 1983;96:1089-96.

[49] Weber JS, Mule JJ. Cancer immunotherapy meets biomaterials. Nature biotechnology. 2015;33:44-5. [50] Prang P, Muller R, Eljaouhari A, Heckmann K, Kunz W, Weber T, et al. The promotion of oriented axonal regrowth in the injured spinal cord by alginate-based anisotropic capillary hydrogels. Biomaterials. 2006;27:3560-9.

[51] Ren D, Yi H, Wang W, Ma X. The enzymatic degradation and swelling properties of chitosan matrices with different degrees of $\mathrm{N}$-acetylation. Carbohydrate research. 2005;340:2403-10.

[52] Zhang $\mathrm{H}$, Neau SH. In vitro degradation of chitosan by a commercial enzyme preparation: effect of molecular weight and degree of deacetylation. Biomaterials. 2001;22:1653-8. 